Canadian Science Publishing

Applied Physiology, Nutrition, and Metabolism Physiologie appliquée, nutrition et métabolisme

\title{
Age-related decline in endurance running performance - An example of a multiple World records holder
}

\begin{tabular}{|r|l|}
\hline Journal: & Applied Physiology, Nutrition, and Metabolism \\
\hline Manuscript ID & apnm-2017-0298.R1 \\
\hline Manuscript Type: & Brief communication \\
\hline Date Submitted by the Author: & 28 -Jul-2017 \\
\hline $\begin{array}{r}\text { Complete List of Authors: } \\
\text { Is the invited manuscript for } \\
\text { consideration in a Special } \\
\text { Issue? : }\end{array}$ & $\begin{array}{l}\text { Cepers, Romuald; INSERM U1093 UFR STAPS DIJON } \\
4334\end{array}$ \\
\hline Keyword: & Case report, master athlete, running < sports, aging, marathon \\
\hline
\end{tabular}




\section{1}

3

4

5

6

7

8

9

10

11

12

13

14

15

16

17

18

19

20

21

22

23

24

25

26

4

16

\section{Age-related decline in endurance running performance - An example of a multiple World records holder}

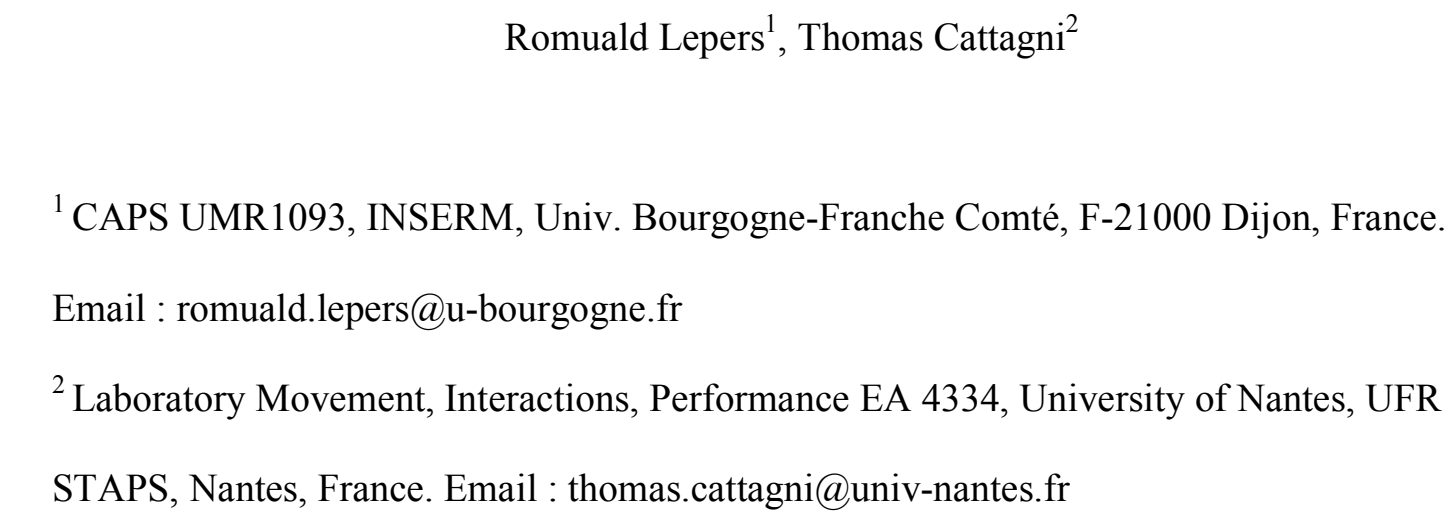

Article type: Brief communication

\section{Corresponding author:}

7 Pr. Romuald Lepers

Laboratoire INSERM U1093 - Cognition Action et Plasticité Sensorimotrice

Faculté des Sciences du Sport

1 Université de Bourgogne

2 BP 27 877, Dijon F-21078, France

3 Email: romuald.lepers@u-bourgogne.fr

4 Tel: +33.380396760

5 Fax : +33.380396702 


\section{Abstract}

28

29 This study examined the age-related decline in endurance running performance of one of the

30 greatest master runners ever, Ed Whitlock. His running performances from $1500 \mathrm{~m}$ to 31 marathon were analyzed for five periods of 5 years from 65-69 years to 85-89 years. Despite 32 exceptional running performances for his advanced age, the rate of decline in his 33 performances increased after 80 years and was drastically amplified after 85 years.

34

35

36 Key words: Case report, master athlete, running, aging, marathon 
38

39

40

41

42

43

44

45

46

47

48

49

50

51

52

53

54

55

56

57

60

61

62

\section{Introduction}

Age-related decline in endurance performance has been well described in literature (Tanaka \& Seals, 2003, Reaburn \& Dascombe, 2008; Lepers \& Cattagni, 2012; Lepers et al., 2016a). The trajectory of this decline is relatively linear since the fourth decade and become exponential after the seventh decade (Rittweger et al., 2009). This accelerated decline sometimes referred to as a "breakpoint" may be explained by several factors such as a reduction of the pool of older competitors, a decrease in the amount and intensity of training or a fading of integrative physiological capacity though training level is maintained (Lazarus \& Harridge, 2017).

The age-related decline in athletic performances is generally assessed by analyzing, for each age-group, world record performances or top finishers in one single event such as world championships. However, these transversal analyses present some limitations because the performances do not belong to the same person and do not correspond to the same generation of athletes. Longitudinal studies would be more appropriated to describe the decline in performance with age but unfortunately, longitudinal studies are scarce in the literature (Trappe et al., 1996; Knechtle et al., 2010). Trappe et al. (1996) investigated runners between 46 and 68 years and found that aerobic capacity of highly trained middle-aged males declined by $5-7 \%$ per decade. Knetchle et al. (2010) reported that the running speeds of a 86 years master runner (winner of the European half-marathon Championship in the 85-89 agegroup) gradually slowed since the age of 64, with a larger decline after 80 years.

In the present paper, we propose to analyze the age-related decline in endurance running performance of one of the greatest master runners ever, Ed Whitlock (EW), (19312017). EW recently died of prostate cancer one week after his $86^{\text {th }}$ birthday. Before that, the Canadian master athlete was the first person over 70 years old to run a marathon in less than 
63 three hours. At the age of 85 , he was also the oldest person to run a marathon in less than four

64 hours. The main aim of this study is to describe the age-related decline in running

65 performance of EW. We more specifically focused on EW's performance after 65 years old

66 because he held his world records in age-groups from 65-69 years onwards.

67

68 Methods

69

70 Data were collected from the following websites: http://www.world-masters-

71 athletics.org; https://www.mastersrankings.com and http://www.arrs.net.

72 To date, EW still held more than 30 age-class world records on road and track

73 running. EW had a late-life career as a marathoner. He ran a 4:31 mile in high school then ran

74 little in college because of an Achilles tendon injury, and quit running at age $21 \mathrm{yrs}$ when he

75 started to work. He resumed running at his 40's and became a world-class masters runner at

$76800 \mathrm{~m}$ and $1500 \mathrm{~m}$. He did his first marathon at age $46 \mathrm{yrs}$ and had his personal best on the

77 marathon at age $48(2 \mathrm{~h} 31 \mathrm{~min} 23 \mathrm{~s})$. After winning the World masters $1500 \mathrm{~m}$ title at age 48

$78 \mathrm{yrs}$, he lost the incentive to train and again stopped running. After retiring, EW took up

79 running again. EW said, "I realized in my late 60 s that this silly objective of being the first

80 person over 70 yrs to get under $3 \mathrm{~h}$ in the marathon was just sitting there waiting for

81 someone." ( $\quad$ http://www.runnersworld.com/ed-whitlock/masters-marathon-legend-ed-

82 whitlock-dies-at-86).

83 The running performances were considered for the categories corresponding to a 584 year period as follows: 65-69 years, 70-74 years, 75-79 years, 80-84 years and 85-89 years.

85 The following running distances were considered: $1500 \mathrm{~m}$ (indoor and outdoor), $3000 \mathrm{~m}$ 86 (indoor and outdoor), $5000 \mathrm{~m}, 10 \mathrm{~km}, 21 \mathrm{~km}$ and the marathon (42 km). The age-related 87 decline in performance was specifically examined for $1500 \mathrm{~m}$ (indoor and outdoor, pool data), 
88

89

90

91

92

93

94

95

96

97

98

99

100

101

102

103

104

105

106

107

108

109

110

111

112

$5000 \mathrm{~m}, 10 \mathrm{~km}$ and marathon $(42 \mathrm{~km})$, and was expressed as the age-related decline in running speed for these four distances.

\section{Results}

2

3

The most representative running performances of EW are shown in table 1 . The mean decrease in running performance between each 5-year period from 65-69 years remained inferior to 5\% until 75-79 years but was more pronounced after 80 years, reaching $13.4 \%$ between 80-84 years and 85-89 years. Figure 1 shows the age-related decrease in running performances during a 20 -year period between 65 and 85 years. The running speed for the different events declined with advanced age but the decline was more pronounced after 80 years old.

\section{Discussion}

The running performances of EW after 65 years old are exceptional. One of the most impressive performances remains maybe his running time at the marathon set at the age of 73 yrs when he ran $2 \mathrm{~h} 54 \mathrm{~min} 48 \mathrm{~s}$. The performance corresponding to a running speed of $4.02 \mathrm{~m} . \mathrm{s}^{-}$

${ }^{1}$ is only $30 \%$ lower than that of the actual absolute world record $\left(5.72 \mathrm{~m} . \mathrm{s}^{-1}, 2 \mathrm{~h} 02 \mathrm{~min} 57 \mathrm{~s}\right)$ and was considered, according to the model proposed by Vanderburgh (2015), as the fastest ageadjusted marathon world records of all time (age-adjusted time: $2 \mathrm{~h} 02 \mathrm{~min} 42 \mathrm{~s}$ ). It has also been estimated that the maximum oxygen uptake $\left(\mathrm{VO}_{2 \max }\right)$ of $\mathrm{EW}$ at 80 years of age was close to $50 \mathrm{mlO}_{2} \cdot \mathrm{kg}^{-1} \cdot \mathrm{min}^{-1}$ (Lepers et al. 2013), that is much higher than the average $\mathrm{VO}_{2 \max }$ observed by Trappe et al (2013) in octogenarian endurance athletes $\left(\sim 38 \mathrm{mlO}_{2} \cdot \mathrm{kg}^{-1} \cdot \mathrm{min}^{-1}\right)$.

Besides his exceptional performances during his last two decades of life, there was an 
113 accelerated decline in his performances after 80 years. The mean decline from $1500 \mathrm{~m}$ to

114 marathon reached $13 \%$ during the 5 -year period between 80 and 85 years, whereas it was only

115 around 5\% under 80 years. Knechtle et al. (2010) reported similar observation for a well-

116 trained master athlete, who presented an increased rate of decline in half-marathon

117 performance at the age of 82 yrs. The reason for this accelerated decline in performances at

118 the beginning of 80 's in master athletes are not clear. Potential age-related changes in

119 physiological determinants of endurance exercise performance have been well described in

120 literature (Lepers et al. 2016a, Tanaka and Seals, 2003). Reductions in $\mathrm{VO}_{2 \max }$, lactate

121 threshold and exercise economy are closely related to reductions in exercise training volume

122 and intensity. The changes in the physical (e.g. prevalence of injuries) and behavioral (e.g.

123 reduction in motivation to train) characteristics of training of the endurance master athletes

124 with age can also be implicated. A possible fading of integrative physiological capacity after

12580 years, though training levels remain appropriated for age, should require more attention by 126 exercise physiologists.

127 We do have some information about EW's training. In interviews (Video available at 128 the address: https:/www.youtube.com/watch?v=65dNE_BMTNc), EW said things like: "I 129 don't have a manager. I don't have a coach. I don't have a trainer. I don't use heart monitors. 130 I don't take any supplements." When at the height of marathon training, Whitlock did 131 cemetery loops for 3 hours a day, every day; doing more than 140 miles per week. However, 132 EW had a competitive spirit, He said: "Age-grading tables are a great motivator. My main 133 interest in them is to see if I'm going downhill faster than the tables say or see if I can beat the 134 tables." Even if, there is few scientific evidence on the way to train master athletes, especially 135 elderly master athlete (Borges et al. 2016), EW would have probably had benefits to train 136 with a coach for master athletes. 
The presence of an accelerated decline in endurance performance after 80 years old

138

139

140

141

142

143

144

145

146

147

148

149

150

151

152

153

154

155

156

157

158

159

160

161

162

163

164

165

166

167

168

169

170

needs to be confirmed by other longitudinal studies for other endurance activities such as swimming and cycling. Indeed, previous studies suggested that age-related decline in endurance performance depended on the locomotion mode, with a less pronounced decline in cycling compared with running or swimming (Bernard et al., 2010; Lepers et al., 2010; Lepers et al., 2016b, Lepers et al., 2017).

In conclusion, the running performances of EW from $1500 \mathrm{~m}$ to marathon from 65 to 85 years were exceptional. His performances showed a more pronounced drop after 80 years old. However as previously mentioned, EW died at 86 years old from prostate cancer and this could have had a significant impact on the EW's running performances during the last years of his life, especially after 85 years.

\section{Conflict of interest}

The authors report no conflicts of interest associated with this manuscript

\section{References}

Bernard, T., Sultana, F., Lepers, R., Hausswirth, C., and Brisswalter, J. 2010. Age related decline in Olympic triathlon performance: effect of locomotion mode. Exp. Aging Res. 36, 115. doi: $10.1080 / 03610730903418620$

Borges, N., Reaburn, P., Driller, M., and Argus, C. 2016. Age-Related Changes in Performance and Recovery Kinetics in Masters Athletes: A Narrative Review. J. Aging Phys. Act. 24, 149-157. doi: 10.1123/japa.2015-0021.

Knechtle, B., Kohler, G., and Rosemann, T. 2010. Study of a European male champion in 10$\mathrm{km}$ road races in the age group $>85$ years. Proc. (Bayl Univ Med Cent). 23(3):259-260.

Lazarus, N.R., and Harridge, S.D. 2017. Declining performance of master athletes: silhouettes of the trajectory of healthy human ageing? J Physiol. 595(9):2941-2948. doi: $10.1113 / \mathrm{JP} 272443$. 
Lepers, R., Sultana, F., Bernard, T., Hausswirth, C., and Brisswalter, J., 2010. Age-related changes in triathlon performances. Int. J. Sports Med. 31, 251-256. doi:10.1055/s-00291243647.

Lepers, R. and Cattagni, T. 2012. Do older athletes reach limits in their performance during marathon running? Age (Dordr). 34, 773-781. doi: 10.1007/s11357-011-9271-z

Lepers, R., Stapley, P.J., Cattagni, T., Gremeaux, V., and Knechtle B. 2013. Limits in endurance performance of octogenarian athletes. J. Appl. Physiol. 114(6):829. doi: 10.1152/japplphysiol.00038.2013.

Lepers, R., and Stapley, P.J. 2016a. Master Athletes Are Extending the Limits of Human Endurance. Front Physiol. 12(7):613. doi: 10.3389/fphys.2016.00613. Review.

Lepers, R., Stapley, P.J., and Cattagni, T. 2016b. Centenarian athletes: Examples of ultimate human performance? Age and Aging. 45(5):732-736. doi: 10.1093/ageing/afw111.

Lepers, R., Stapley, P.J., and Cattagni, T. (2017) Age-Related Changes in Endurance Performance Vary Between Modes of Locomotion in Men: An Analysis of Master World Records. Int. J. Sports Physiol. Perform. 17:1-12. doi: 10.1123/ijspp.2017-0222.

Reaburn, P., and Dascombe, B. 2008. Endurance performance in masters athletes. Eur. Rev. Aging Phys. Act. 5: 31-42.

Rittweger, J., di Prampero, P.E., Maffulli, N., and Narici, M. V, 2009. Sprint and endurance power and ageing: an analysis of master athletic world records. Proc. Biol. Sci. 276, 683-689. doi:10.1098/rspb.2008.1319.

Tanaka, H., and Seals, D.R. 2003. Invited Review: Dynamic exercise performance in Masters athletes: insight into the effects of primary human aging on physiological functional capacity. J. Appl. Physiol. 95, 2152-2162.

Trappe, S.W., Costill, D.L., Vukovich, M.D., Jones, J., and Melham, T. 1996. Aging among elite distance runners: a 22-yr longitudinal study. J. Appl. Physiol. 80(1):285-290.

Trappe, S., Hayes, E., Galpin, A., Kaminsky, L., Jemiolo, B., Fink, W., Trappe, T., Jansson, A., Gustafsson, T., Tesch, P. 2013. New records in aerobic power among octogenarian lifelong endurance athletes. J. Appl. Physiol. 114(1):3-10.

Vanderburgh, P.M. 2015. Fastest age-adjusted marathon world records of all time. Med. Sci. Sports Exerc. 47, Issue 5S - p 420. doi: 10.1249/01.mss.0000477575.32852.9b 


\begin{tabular}{|c|c|c|c|c|c|c|c|c|c|}
\hline \multirow{2}{*}{$\begin{array}{l}\text { Age } \\
\text { Group }\end{array}$} & \multicolumn{2}{|c|}{$1500 \mathrm{~m}$} & \multicolumn{2}{|c|}{$3000 \mathrm{~m}$} & \multirow{2}{*}{$\begin{array}{l}5000 \mathrm{~m} \\
(\min : \mathrm{s},)\end{array}$} & \multirow{2}{*}{$\begin{array}{l}10 \mathrm{Km} \\
\text { (min:s,) }\end{array}$} & \multirow{2}{*}{$\begin{array}{c}21 \text { km } \\
\text { (h:min:s) }\end{array}$} & \multirow{2}{*}{$\begin{array}{l}\text { Marathon } \\
\text { (h:min:s) }\end{array}$} & \multirow{2}{*}{$\begin{array}{c}\text { Mean difference } \\
\text { with previous } \\
\text { age group }\end{array}$} \\
\hline & $\begin{array}{l}\text { Outdoor } \\
\text { (min:s,) }\end{array}$ & $\begin{array}{l}\text { Indoor } \\
\text { (min:s,) }\end{array}$ & $\begin{array}{l}\text { Outdoor } \\
\text { (min:s,) }\end{array}$ & $\begin{array}{l}\text { Indoor } \\
\text { (min:s,) }\end{array}$ & & & & & \\
\hline $65-69$ yrs & $04: 46,1$ & & & & $17: 38,5$ & $36: 31,5$ & 01:19:32 & 02:51:02 & \\
\hline $70-74$ yrs & $05: 07,9$ & & & $10: 52,4$ & $18: 33,4$ & $38: 04,1$ & $01: 22: 23$ & 02:54:48 & $4.7 \pm 1.8 \%$ \\
\hline $75-79$ yrs & & $05: 20,0$ & $11: 10,4$ & $11: 17,2$ & $19: 07,0$ & $39: 25,2$ & $01: 29: 26$ & 03:04:54 & $4.3 \pm 1.9 \%$ \\
\hline $80-84$ yrs & & $05: 48,5$ & $12: 13,6$ & $12: 08,9$ & $20: 58,1$ & $42: 39,9$ & 01:37:38 & 03:15:54 & $8.1 \pm 1.4 \%$ \\
\hline $85-89$ yrs & $06: 38,2$ & $06: 38,9$ & & $13: 42,0$ & $24: 03,9$ & $51: 07,5$ & & 03:56:34 & $13.4 \pm 2.9 \%$ \\
\hline
\end{tabular}

Table 1. Selection of representative running performances of Ed Whitlock. In bold : Current world records. 


\section{Figure captions}

\section{Figure 1}

Ed Whitlock's running speed as function of age for different events. The decline becomes more predominant after 80 years old.

225

226 


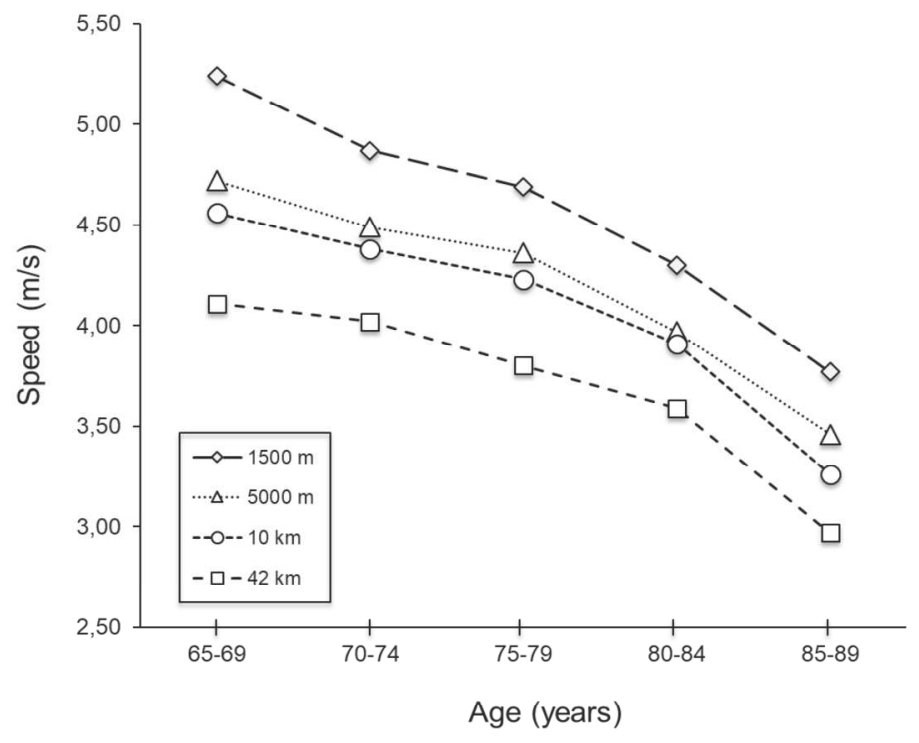

Figure 1

Ed Whitlock's running speed as function of age for different events. The decline becomes more predominant after 80 years old.

$138 \times 89 \mathrm{~mm}(600 \times 600 \mathrm{DPI})$ 